\title{
A molecular link between vascular disease, platelet activation and tissue fibrosis in SSc
}

"Inhibition of $5-\mathrm{HT}_{2 \mathrm{~B}}$ receptors might be a promising new therapeutic approach for systemic sclerosis," claims Jörg H. W. Distler, based on the results of a paper from his research group now published in The Journal of Experimental Medicine.

Vascular damage and platelet activation are known to precede tissue remodeling and fibrosis in patients with systemic sclerosis (SSc), but how these processes are linked at the molecular level is unknown.

The authors of this study focused on serotonin (5-hydroxytryptamine [5-HT]), which is released by platelets on activation and is present at higher than normal levels in the blood of SSc patients.

First, the researchers showed that 5-HT-stimulation of dermal fibroblasts from patients with SSc and healthy controls resulted in a dose-dependent increase in the production of extracellular matrix proteins by these cells. Of the three 5-HT receptors expressed by dermal fibroblasts, 5-HT was shown to

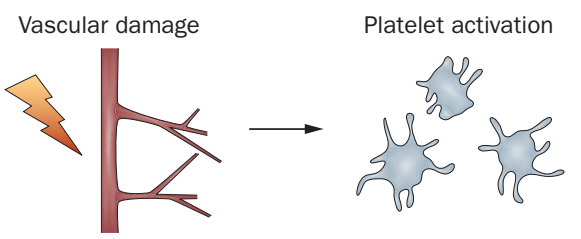

mediate its effects by selectively activating $5-\mathrm{HT}_{2 \mathrm{~B}}$ receptors, which were shown to be expressed at higher levels in fibrotic skin from SSc patients than in normal skin from healthy controls.

Next, the effect of ablating $5-\mathrm{HT}_{2 \mathrm{~B}}$ receptor signaling in the mouse model of bleomycin-induced dermal fibrosis was investigated. Dermal thickening was blocked in mice treated with 5-HT-receptor inhibitors, or a selective $5-\mathrm{HT}_{2 \mathrm{~B}}$ receptor inhibitor, in comparison with control mice that were challenged with bleomycin but received no other treatment. In addition, 5- $\mathrm{Htr} 2 \mathrm{~b}^{-/}$ mice were protected against bleomycininduced dermal fibrosis, as were mice that selectively lacked expression of 5-HT in

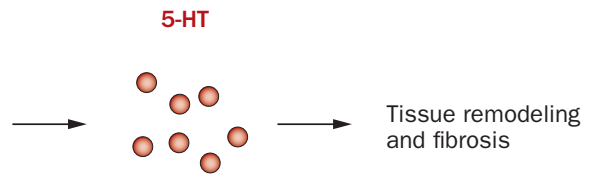

their platelets. Finally, blocking platelet activation resulted in reduced levels of 5-HT and "prevented fibrosis in different mouse models resembling early and late stages of SSc," states Distler.

The authors believe that these findings have direct clinical implications for the future therapy of fibrotic disorders, including SSc. Indeed, as Distler concludes, "the first proof-of concept trial to evaluate the anti-fibrotic effects of $5-\mathrm{HT}_{2 \mathrm{~B}}$ inhibition in SSc is ongoing."

Jenny Buckland

Original article Dees, C. et al. Platelet-derived serotonin
links vascular disease and tissue fibrosis. J. Exp. Med.
doi:10.1084/jem. 20101629

